\title{
Carbon credits for the Joneses
}

It sounds like a triumph for the doctrine that people should think globally but act locally — and like a nightmare scenario for libertarian opponents of big government. Last week, UK environment secretary David Miliband suggested issuing all British adults with an annual carbon allowance. Advocates say the system is fair and would focus people's attention on conserving energy. But could it ever succeed?

Here is how the system would work. For transactions that involve direct purchases of energy, such as buying petrol or paying fuel bills, a person would hand over money and some of the carbon credits he or she had been allocated by government. If those credits ran out, the person would have to buy extra when paying for the fuel or electricity. By regulating the amount of personal credits handed out each year, the government could cap total carbon emissions and help tackle climate change.

"Instead of banning particular products, services or activities — or taxing them heavily
- a personal carbon allowance enables citizens to make trade-offs," said Miliband as he floated the idea on 19 July.

Civil servants will look into the proposal and report back to government next year. Researchers who have studied the idea say domestic quotas are a sensible way to extend emissions trading to the personal level - such trading is already used to limit emissions from some European industries. And unlike a blanket

\section{"It would be awfully} hard to explain this to Americans." a car that uses petrol would use about $1 \%$ of that The allowance would be worth only a few tens of pounds (or US dollars) at today's prices, but if policies are enacted to meet the ambitious UK target of reducing emissions to 60\% below 1990 levels by 2050, that would rise significantly.

Such ideas are going down rather less well in the United States, where environmental activists privately hope the UK proposal will attract as little attention as possible. Oil-industry groups carbon tax, it encourages individuals to think about their emissions. "It makes carbon more visible," says Richard Starkey, a carbon-policy expert at the University of Manchester, UK.

Starkey also points out that low-income families, which tend to use less energy than higher earners, could save and then sell carbon credits. At current UK emission levels, he reckons each individual would receive around 1.25 tonnes of carbon. For an idea of scale, a $200-\mathrm{km}$ journey in have previously claimed that attempts to tackle climate change such as the Kyoto Protocol will damage lifestyles - an accusation that most politicians, particularly in the United States, are careful to avoid. Personal carbon credits may sound too much like energy rationing. "It would be awfully hard to explain this to Americans," says one senior US environmental advocate, who asked not to be named.

Jim Giles 